\title{
1 The use of non-destructive testing to evaluate the compressive strength 2 of a lime-stabilised rammed-earth wall: Rebound index and ultrasonic pulse velocity
}

4 Juan Jesús Martin-del-Rio ${ }^{1, a}$, Jacinto Canivell ${ }^{2, a^{*}}$, Raúl M. Falcón ${ }^{3, b}$

5 a Department of Architectural Construction II, Universidad de Sevilla, Av. Reina Mercedes 4, 41012 Sevilla, 6 Spain.

${ }^{\mathrm{b}}$ Department of Applied Mathematics I, Universidad de Sevilla, Av. Reina Mercedes 4, 41012 Sevilla, Spain.

1iidelrio@us.es, ${ }^{2}$ jacanivell@us.es, ${ }^{3}$ rafalgan@us.es

$9 *$ Corresponding author.

Abstract. The non-standardization of rammed earth construction involves the quality control of such a technique to be so troublesome that it is generally avoided. As a possible approach to improve the mentioned quality control, this paper deals with a series of univariate and multivariate statistical analyses concerning the correlation between a pair of non-destructive testings (rebound index and ultrasonic pulse velocity) and the compressive strength of a specific composition of rammed earth. Both non-linear (univariate) and linear (multivariate) regression models are established so that the variability of the compressive strength is accurately explained by means of both kind of non-destructive testings.

Highlights: index. prediction of CS. standards on concrete. 
27 Keywords: Rammed earth, ultrasonic test, rebound hammer, compressive strength, nondestructive testing.

\section{Introduction}

In spite of the existence of some handbooks, guides and standards that make easier the design and site work of rammed earth construction in several countries, the quality control of such a technique is particularly difficult to be objective and quantitatively managed.

Constructive materials of rammed earth (sand and gravel, clay, stabilizers, water and additives) have been dealt with in the literature as criteria to get a minimum quality level that is based on both compressive strength and other durability factors (retraction level and cracking, or cohesion and surface strength) [1-4]. Even if all such references explain how a rammed-earth wall is properly constructed, only few of them focus on the evaluation of its quality of execution $[5,6]$. Such an evaluation is much easier in case of dealing with techniques using industrialised materials (concrete, mortar or cooked brick), because their samples are more representatives. Moreover, there exist some guidelines or technical recommendations that regulate how to do the corresponding quality test [7-9]. In these cases, the quality is mostly evaluated according to the compressive strength of samples.

Concerning rammed earth, there rarely exist studies on this topic. Some of them make use of destructive methods as, for instance, sample extraction, which is used to determine the unconfined compressive strength on executed walls [10]; or cored samples [11], which are extracted by means of drills in both compaction and transversal directions. In this last reference, it is shown that cored samples modify both mechanical and physical properties of a rammedearth wall, probably due to the contribution of water to cuts and vibrations. Moreover, even if a number of samples are elaborated from the same dosages, they are approximations of an onsite executed wall, because compressive strengths by both means are not equal. 
Some other authors, in case of dealing with historical rammed-earth walls, choose to engrave cubical samples from rammed-earth blocks extracted from representative and almost unaltered places [12]. The cutting of this type of samples is not always possible, because of its low cohesion and high porosity. As a consequence, it is only possible to get a small number of such samples and hence, the related results are not very representative. Moreover, the existence of different sample sizes implies that the comparison among results is not direct, hence the results have to be corrected according to their size [11] and slenderness [6,13]. In any case, sample extraction in a rammed-earth wall can critically modify the outer appearance of the wall, even without ensuring that samples are either enough unaltered or in the right position to get enough representative or accurate mechanical tests. Another option aims the use of minor destructive testings, as those proposed in [14], where it is shown in a preliminary way how flat Jack and hole-drilling test can be used to determine accurately the compressive strength.

Concerning non-destructive testings (NDT), ultrasonic pulse velocity (UPV) is used as a complementary test in some materials such as concrete $[15,16]$. Regarding rammed earth, NDT have been used to evaluate its elastic modulus, its moisture content (MC) [17], discontinuities in historical walls [18] or the unconfined compressive strength [19]. Vibration measurement has also been used in rammed earth for evaluating its elastic modulus [20]. In the case of concrete, the evaluation of compressive strength by means of both superficial hardness and rebound index is stated by UNE-EN-13791:2009 [16]. In rammed earth, some experiments have been done by making use of different types of sclerometers. In this regard, some authors suggest the use of the original Schmidt hammer series NR/LR [21] or similar ones [22,23], which are more commonly used in concrete structures, whose compressive strength usually ranges within the interval $10-100 \mathrm{~N} / \mathrm{mm}^{2}$. Nevertheless, these values are far away from those ones established by some authors for rammed earth $[24,25]$. There are sclerometers that are designed for softer materials, like rammed earth, whose unconfined compressive strength (UCS) is normally lower than $5 \mathrm{~N} / \mathrm{mm}^{2}$. Thus, for instance, authors in [26] make use of the model Schmidt OS-120PT, 
although the calibration curves of the manufacturer are considered, which in fact are not designed for rammed earth. Even if some other authors make use of the aforementioned tool, it has been applied on rammed-earth renders [27] and following the technical recommendations of RILEM [9].

All the mentioned studies constitute a preliminary advance on the development of NDT, but it is still necessary much more experimentation in order to establish efficient methods. Moreover, it is necessary to determine some kind of criteria in order to implement NDT in a more rigorous way that allows the experimentation to be more reproducible. In this regard, the recent paper [21] constitutes a detailed study for rammed earth, although it makes use of a tool that is more adequate for superficial harder materials, like concrete. Nevertheless, the proposal of a new calibration method is novel and offers positive results concerning its implementation.

Despite other more industrialised materials (such as concrete, mortar or fired brick), the quality evaluation of rammed earth by means of samples made on-site or cored samples is complicated. Keeping this fact in mind, this paper introduces the existing correlation among two NDT (ultrasonic pulse velocity and rebound index) and the unconfined compressive strength on a rammed-earth wall with a specific dosage, which can be used to evaluate the quality of the wall in a flexible and fast way, without damaging it. In any case, it is remarkable the fact that these two NDT do not constitute substitutes of direct tests, but complementary methods that can be useful to determine the mechanical behaviour of a lime-stabilised rammed-earth wall. Further, UNE standards for concrete $[9,22]$ are revised and adapted to the aim of this study.

\section{Material and methods}

The rammed earth that was used in this study consisted of a mixture sub-soil, and hydraulic lime HL5. The dosage to construct samples of rammed earth was 411; that is, four parts of dry soil, one part of water and one part of the hydraulic lime HL-5, according to the coding system proposed by Hall and Djerbib [28]. 
Soil suitability was studied and assessed by means of on-site tests [29] (drop test, ribbon test,

103 visual inspection, sedimentation) and laboratory tests: particle size distribution [30], plasticity limits [31,32], X-ray powder diffraction (XRD) proposed for determining overall mineralogy, organic matter content $[33,34]$ and optimum water content [35].

A procedure to elaborate rammed earth specimens was developed in accordance with recommendations provided in international standards and manuals $[6,13,25]$, and involving cube and cylindrical rammed earth samples. In order to obtain statistically representative results, 48 prismatic samples were gathered in 24 batches of two samples of $15 \times 15 \times 20 \mathrm{~cm}$. Moulds in the current study have inner dimension $15 \times 15 \times 30 \mathrm{~cm}$ (Fig. 1). It makes possible the construction of $15 \times 15 \times 20 \mathrm{~cm}$ prismatic test tubes by means of four earth layers. The first three layers determine a sample $A$ of $15 \mathrm{~cm}$ height, whereas sample B corresponds to the last layer, which is separated from the rest by means of a plastic sheet. The latter was used to determine both porosity and density. According to the UNE-EN 12504-1 standard [15], the size of a cube specimen must comply with the ratio $1: 3$ between the maximum aggregate size and the test specimen edge. Consequently, particles larger than $3.15 \mathrm{~cm}$ were discarded. Samples were identified from 1 to 48 .

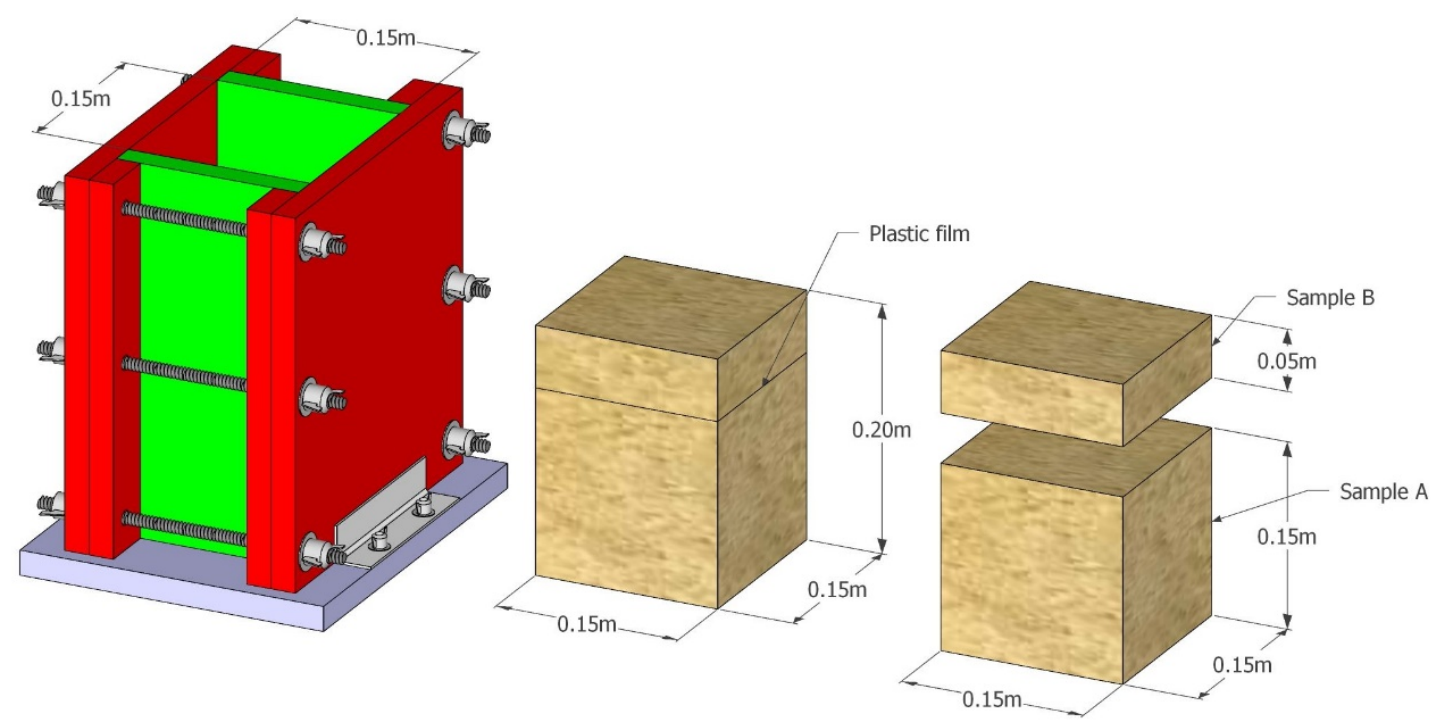


121 Optimum moisture content (OMC) and maximum dry density (D) were determined by the 122 Proctor compaction method [35]. In order to get an earth mix moisture as uniform as possible 123 to deal with test samples, the following procedure was implemented. Firstly, the soil was kiln 124 dried $\left(100^{\circ} \mathrm{C}\right) 48-72$ hours to get a constant moisture with a $0-1 \%$ variation. Once the soil was cooled down, it was dried mixed with lime during 60-90 seconds in a concrete steel drum mixer. Next, an enough quantity of water was added to the soil to get the OMC established value, and then it was mixed by hand in order to get a uniform mix, since dry mixtures are not suitable for the above mentioned equipment. At that moment, two soil samples were taken to determine the mean of the moulding moisture content (MMC) according to the UNE-EN-ISO-17892-1 standard [36].

In order to get uniformity in the compaction among the 48 test tubes, the ratio between compaction energy and volume was established according to the Proctor test [35]. The procedure to do it was similar to those ones described in [11,37], but considering manual compaction instead of mechanical means. Moreover, equations (1) to (3) were established to determine the number $n_{m}$ of strokes that are necessary to get the reference compaction energy (3). Since manual ramming was applied, it was necessary to establish the number of strokes (3), by considering to this end that the energy per volume of layer of cube samples (1) is equal to the energy per volume of layer of the Proctor sample (2):

$$
e_{m}=\frac{\left(M_{m} \times g \times h_{m}\right) \times n_{m}}{V_{m}}
$$

$$
e_{O M C}=\frac{\left(M_{O M C} \times g \times h_{O M C}\right) \times n_{O M C}}{V_{O M C}}
$$

$$
e_{m}=e_{O M C}=\frac{\left(M_{m} \times g \times h_{m}\right) \times n_{m}}{V_{m}} \Rightarrow n_{m}=\frac{e_{O M C} \times V_{m}}{\left(M_{m} \times g \times h_{m}\right)} \text { (3) }
$$


142 Here, $e_{\text {oMc }}=194.28 \mathrm{~kg} \cdot \mathrm{m}_{2} / \mathrm{s}^{2} ; \mathrm{M}_{\mathrm{m}}$ is the weight of the rammer $(3.28 \mathrm{~kg}) ; \mathrm{g}$ is the gravity acceleration $\left(9.8 \mathrm{~m} / \mathrm{s}^{2}\right) ; \mathrm{h}_{\mathrm{m}}$ is the drop height of the rammer $(0.2 \mathrm{~m})$ and $V_{\mathrm{m}}$ is the volume of the layer of the cube sample $\left(11.25 \times 10^{-4} \mathrm{~m}^{3}\right)$.

To that end, compaction energy per volume was controlled by the weight of the rammer, in addition to the number of strokes and the free fall height of the rammer. The compaction energy per volume for manual ramming must correspond to the Proctor test.

In order to get the same MC for all A samples, they were treated for 27 days under the same environmental conditions ( $20^{\circ} \mathrm{C} \pm 2{ }^{\circ} \mathrm{C}$ and $65 \pm 5 \%$ relative humidity). After that, they were dried during 24 hours by heater at $90^{\circ} \mathrm{C}$, until constant weight, because the variable $\mathrm{MC}$ alters the ultrasonic measures according to the appendix UNE-EN 12504-4 [15], together with its mechanical behaviour. Finally, test samples were cooled down within a hermetic recipient. In this way, the variable $M C$ was then obtained before the determination of the rebound index $(R)$, the ultrasound pulse velocity (UPV) and the CS. Once cured and dried, open porosity (P) and dry density (D) were obtained for B samples by means of a water saturation method in vacuum. To that end, dry, saturated and hydrostatic weights were established as provided in [38]. (UltraTest $\mathrm{GmbH}$ ), having a frequency of $40 \mathrm{kHz}$ according to the manufacturer specifications, and following the procedures established in the UNE-EN standard [15]. In order to verify all the readings, that regulation establishes a $1 \%$ of variability in the mean of at least three values. Even if this range was initially considered in this study, it became too restrictive for a rammed-earth wall, because of the heterogeneity of the rammed-earth samples. As a consequence, after several iterations, it was concluded that the variation among propagation times over samples should be within the $\pm 10 \%$ of the mean of four readings. After implementing this last verification, some values were discarded and it was obtained the mean of all those readings that 
167 pulse velocities: X-UPV and Y-UPV for those directions that are perpendicular to the compaction 168 direction, and Z-UPV for the compaction direction.

169 Since the obtained results may depend on the variability of the sample tests, the sample size has 170 been chosen large enough to ensure that each one of the variables under study is well-modeled 171 by a normal distribution. In any case, such normality has been ensured by performing a Pearson's chi-squared test for the sample tests concerning each variable separately. The results of such a test are shown in Table 1, where the goodness of fit of the normal model derives from the fact that all the corresponding $p$-values are greater than 0.5 .

\begin{tabular}{cccccccc}
\hline Variables & $\mathrm{D}\left(\mathrm{Kg} / \mathrm{cm}^{3}\right)$ & $\mathrm{P} \%$ & $\mathrm{CS}(\mathrm{MPa})$ & $\begin{array}{c}\mathrm{X}-\mathrm{UPV} \\
(\mathrm{Km} / \mathrm{s})\end{array}$ & $\begin{array}{c}\mathrm{Y}-\mathrm{UPV} \\
(\mathrm{Km} / \mathrm{s})\end{array}$ & $\begin{array}{c}\text { Z-UPV } \\
(\mathrm{Km} / \mathrm{s})\end{array}$ & $\mathrm{R}$ \\
\hline Statistic & 14.25 & 18.75 & 6.00 & 9.00 & 14.25 & 14.25 & 18.75 \\
P-value & 0.51 & 0.23 & 0.98 & 0.88 & 0.51 & 14.25 & 0.23
\end{tabular}
Table 1. Summary statistics of Pearson's chi-squared test for all variables under study.

176 In order to execute the rebound index test according to the UNE-EN 12504-2 standard [39], it was used a rebound pendular hammer Schmidt OS-120PT, which is made to carry out tests in softer materials such as early-stage concrete, aerated concrete, plaster panels or mortars, which are more similar to rammed earth. Since this tool is not configured to deal with this last material, it is necessary to calibrate it for establishing the new corresponding curves between R and CS. This is indeed one of the aims of this study. In this regard, keeping in mind the instructions of the aforementioned UNE standard, the test was done for 28 days-aged samples, by means of four readings over each one of the four vertical faces and over the base of the A samples. In this way, 20 readings were obtained; that is, nine more readings than those ones that are recommended in [39]. The rebound hammer was set for its horizontal configuration, as stated in the manufacturer manual, whereas all the test specimens were supported by a levelled and solid base in order to avoid vibrations. It was not possible to make use of the upper face due to the rammer irregularities during compaction. Distances to the specimen borders were saved between strokes (fig. 2) by searching always a smooth-and-free surface of superficial loose stones and discarding the repetition of readings within the same hitting zone. Before any impact, 
the surface was brushed and loss material removed by means of a gridding stone. The median of the total readings was determined for each test sample. In order to validate the determination, it was checked the non-existence of more than $20 \%$ of readings with more than $30 \%$ median deviation, in whose case all of them would be discarded, as it is suggested by the corresponding UNE standard [39].
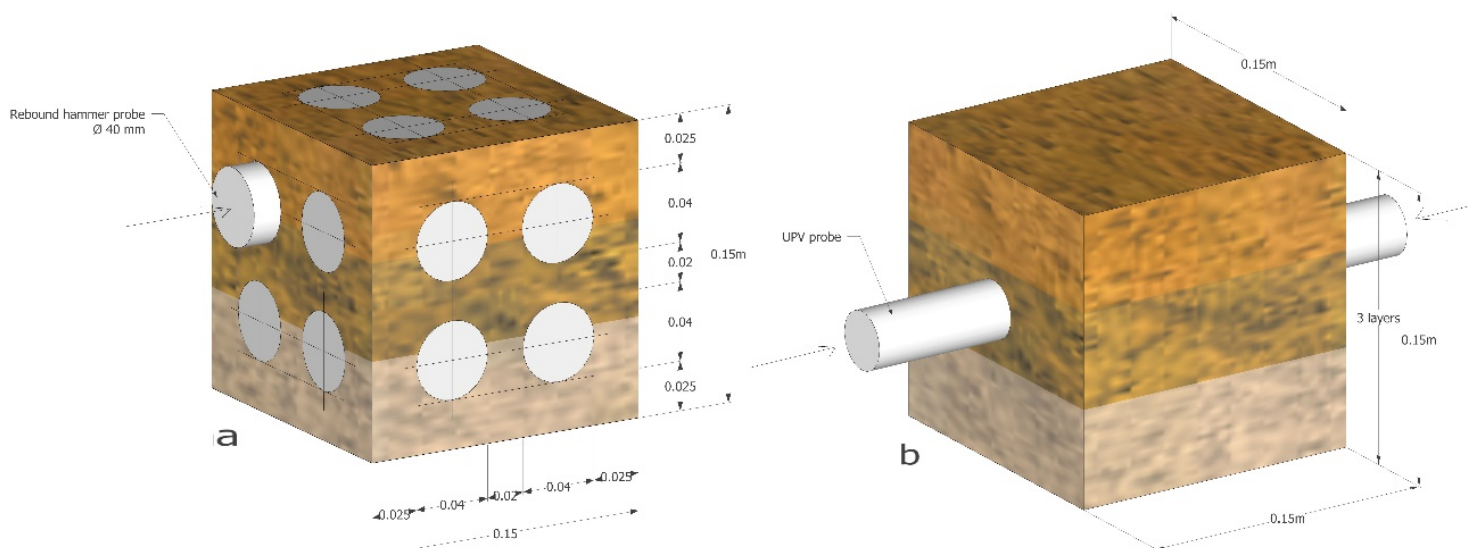

Fig. 2. Cube specimen of rammed earth. Rebound hammer (a) and UPV (b) tests.

CS was determined at 28 days ageing by using an electromechanical strength testing machine (TCCSL model PCI-30t) equipped with a 30-t load cell, with a loading rate of $330 \mathrm{~N} / \mathrm{s}$ and breaking times of 30-90 s, by following to this end the procedure described in the UNE-EN 1015-11 standard [8]. This value corresponds to the interval that is established for mortars $(5-500 \mathrm{~N} / \mathrm{s})$ and also proposed by Hall and Djerbib [28]. The same 48 specimens tested to determine UPV and $\mathrm{R}$ were capped with sulfur mortar and tested in the orthogonal orientation of compaction layers in order to determine CS.

\section{Results}

\subsection{Results on raw materials}

Sub-soil was analysed in terms of particle size distribution and is shown in Figure 3. The upper and lower limits corresponded to Hall and Djerbib [28] and should be taken as an approximate guide, since rammed earth margins are usually rather wide. It can be observed that the grain size distribution was comprehended between the two given limits, and without any 
211 discontinuity. Moreover, fine fraction (silt and clay) as represented in figure 3 were adequately

212 chosen. As a consequence, the proposed particle size distribution constitutes an adequate consideration for elaborating rammed earth.

214

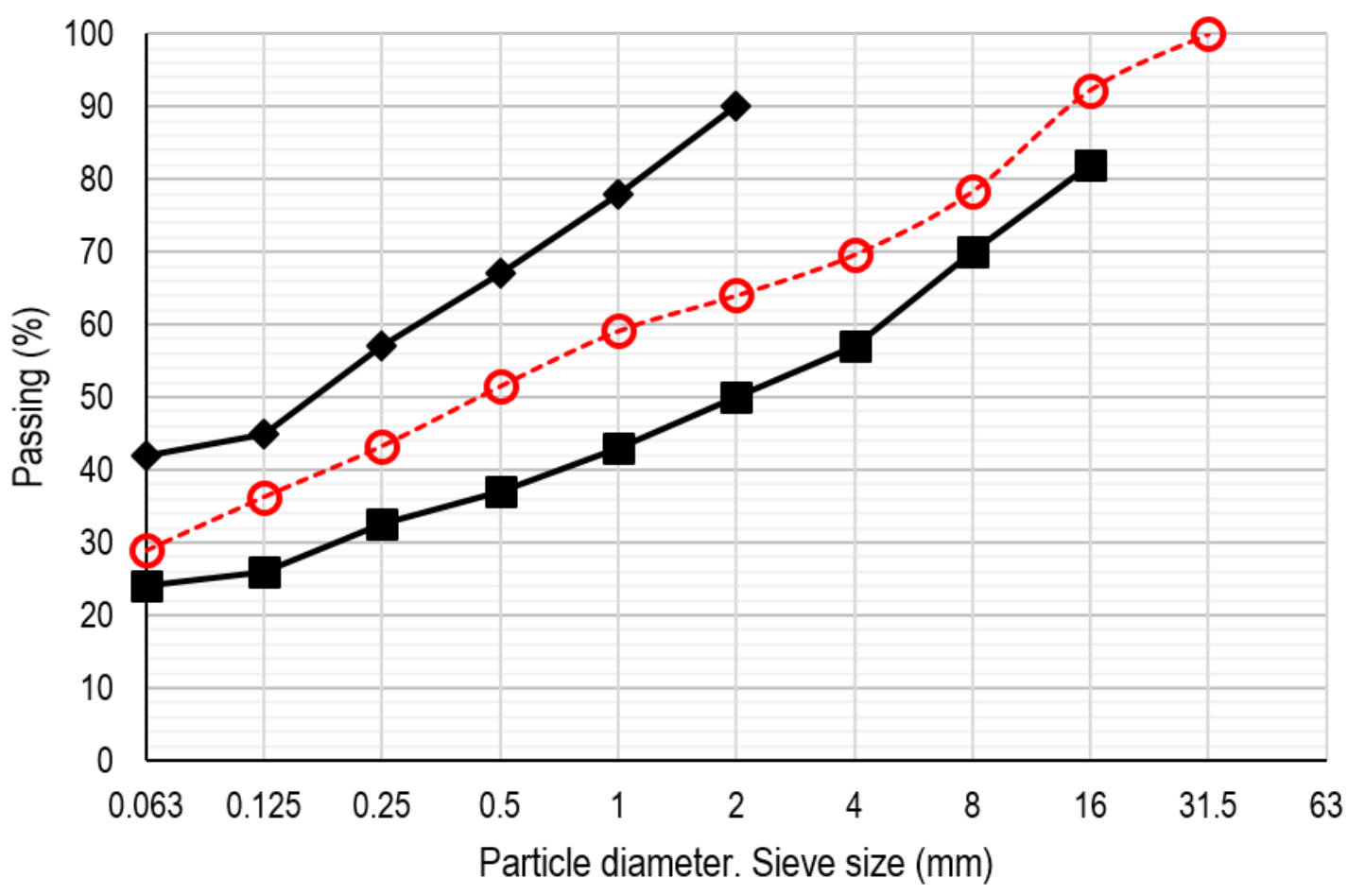

216 Fig. 3. Particle grading curves for sub-soil.

217 OMC was established for the complete dosage (lime included) in accordance with the UNE 103-

218500 standard [35] and is shown in Figure 4. OMC is $11 \%$, corresponding to a dry density of 2.04 $\mathrm{g} / \mathrm{cm}^{3}$. These values served as a reference to be followed during sample production. 


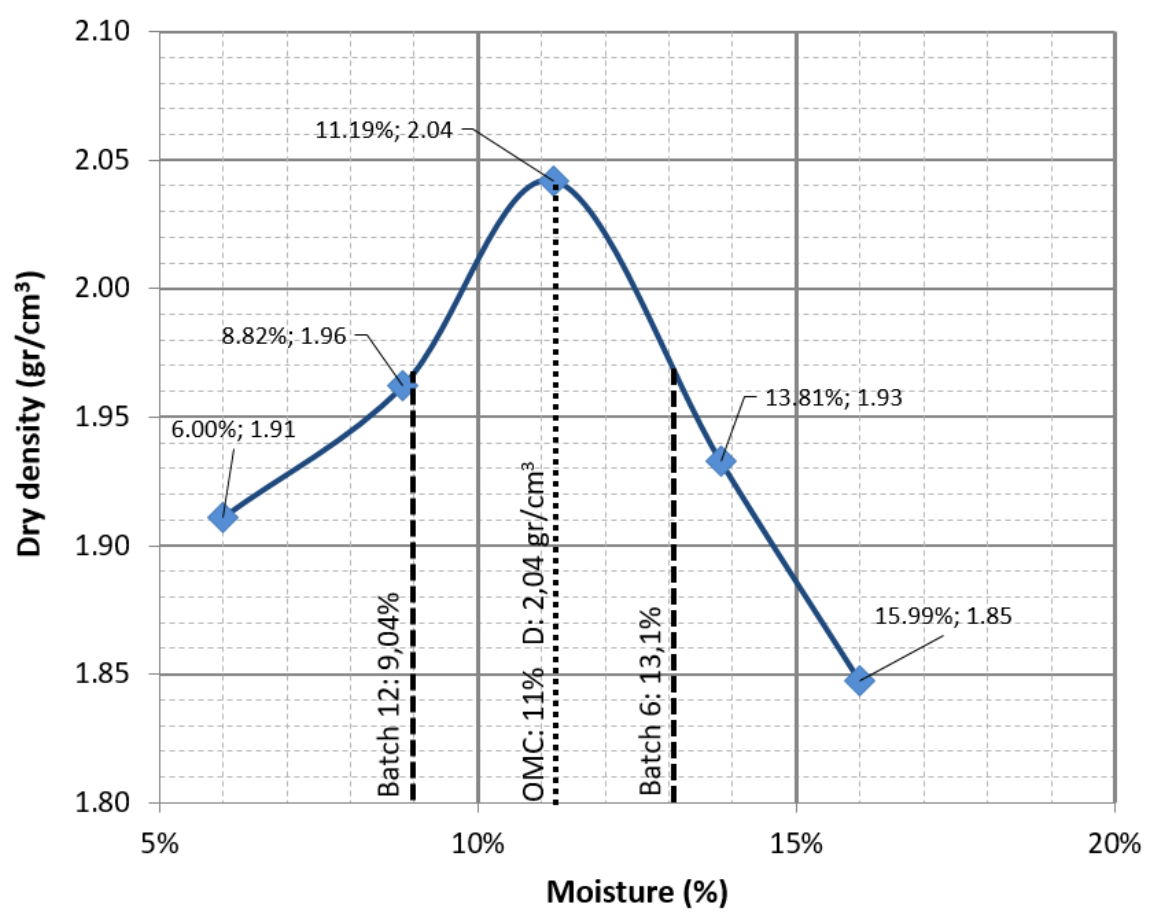

Fig. 4. OMC for the complete dosage and MC for all the batches.

222 The ground plastic limit test was executed according to the UNE 103-104-93 standard [32], with 223 a result of $16.60 \%$. Moreover, the liquid limit determination was executed according to the UNE 103-103-94 standard [31], with a result of $19.1 \%$. Hence, the plasticity index is 2.5 . According to Casagrande's classification for fine soils, it corresponds to the code ML, and thus, the majority of materials passing through the $0.063 \mathrm{~mm}$ sieve would be silt. The MMC mean for all mixes was $11 \% \pm 2 \%$. Concerning the parameter $\mathrm{MC}$, determined after the aforementioned procedure, it is established within the interval $1.6 \% \pm 0.5 \%$, which constitutes an indicative of a similar MC for all test specimens. Hence, given the referred result, $\mathrm{MC}$ is not considered as a variable to predict the mechanical behaviour, although its influence is well-known [40]. The mineral phases identified in the mixture of aggregates (Fig. 5) were as expected taking into account the nature of their components, calcite and quartz being the main minerals, together with K-feldespars (microcline). 


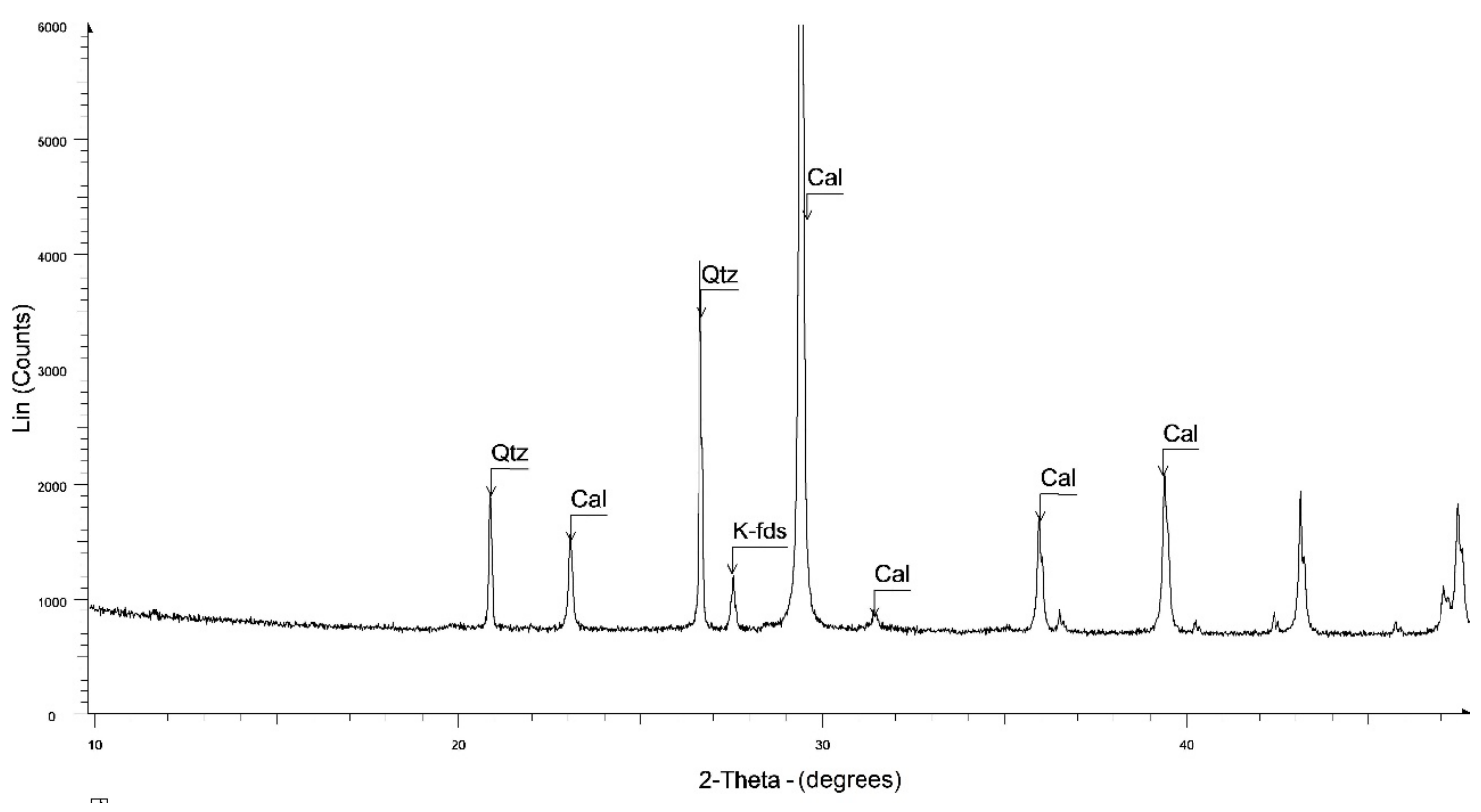

Fig. 5. XRD diagram corresponding to the selected sub-soil.

\subsection{Physical-mechanical properties}

All the results regarding the physical-mechanical variables considered are represented in table

1, whereas table 2 contains parameters such as the mean value, the standard deviation, and the coefficient of variation, which are used to describe the distribution of values within its corresponding ranges.

Density (D) and porosity $(P)$ are opposed parameters that are related to both the mechanical behaviour of rammed earth and durability [41]. Despite that, the direct correlation of both parameters with CS is still being discussed [28]. The results here exposed show similar values for both parameters $D$ and $P$, for all 48 given test samples (table 1). More specifically, these values are respectively comprehended within the intervals $1.87-2.06 \mathrm{~kg} / \mathrm{cm}^{3}$ and $22-30 \%$, approximately. As expected, the lower the $D$, the higher the $P$. The porosity values were therefore comprehended within the range of others for lime-stabilised rammed earth [41], but corresponding to a denser rammed earth. The mean value of $P$ is $27.9 \%$ with a standard deviation of 1.5. Further, the mean of density values is $1.94\left(\mathrm{Kg} / \mathrm{cm}^{2}\right)$, with a standard deviation of 0.04 , as depicted in table 2 . 
253 recommended CS as established in the NZS 4298 standard [6] and in Standards Australia [13].

254 The $92 \%$ of CS is comprehended within the interval $1.3-3.76 \mathrm{MPa}$, with mean of $2.21 \mathrm{MPa}$,

\begin{tabular}{|c|c|c|c|c|c|c|c|c|c|c|c|c|c|c|c|c|}
\hline Specimens & 1 & 2 & 3 & 4 & 5 & 6 & 7 & 8 & 9 & 10 & 11 & 12 & 13 & 14 & 15 & 16 \\
\hline $\mathrm{D}(\mathrm{Kg} / \mathrm{c}$ & 06 & 1.99 & 2.00 & 1.90 & 1.93 & 1.99 & 1.92 & 1.96 & 1.97 & 1.89 & 2.01 & 1.95 & 2.00 & 1.91 & 1.95 & 1.92 \\
\hline $\mathrm{P}$ & 2.6 & 25.9 & 25.4 & 29.1 & 28.3 & 25.6 & 28.5 & 27.1 & 26.8 & 29.8 & 25.5 & 27.5 & 25.2 & 28.9 & 27.4 & 28.6 \\
\hline CS $(\mathrm{N}$ & 2.75 & 2.61 & 1.74 & 1.7 & 2.87 & 3.07 & 2.18 & 1.49 & 3.50 & 2.53 & 2.39 & 1.59 & 3.31 & 3.72 & 3.76 & 2.97 \\
\hline K-UPV & 14 & 1.92 & 1.94 & 1.90 & 1.94 & 2.06 & 1.79 & 1.94 & 1.82 & 1.87 & 1.91 & 1.98 & 2.06 & 2.15 & 2.05 & 2.07 \\
\hline Y-UPV $(\mathrm{Km} / \mathrm{s})$ & 2.28 & 2.14 & 2.29 & 2.18 & 2.23 & 2.07 & 1.87 & 2.15 & 2.04 & 2.16 & 2.10 & 1.91 & 2.20 & 1.92 & 2.27 & 2.17 \\
\hline Z-UPV( & 1.57 & 1.77 & 1.55 & 1.64 & 1.66 & 1.49 & 1.74 & 1.86 & 1.50 & 1.75 & 1.59 & 1.62 & 1.75 & 2.09 & 1.83 & 1.96 \\
\hline $\mathrm{R}$ & 67 & 53 & 43 & 50 & 56 & 54 & 56 & 67 & 59 & 58 & 61 & 62 & 66 & 66 & 57 & 56 \\
\hline Specimens & 17 & 18 & 19 & 20 & 21 & 22 & 23 & 24 & 25 & 26 & 27 & 28 & 29 & 30 & 31 & 32 \\
\hline $\mathrm{D}$ & 1.96 & 94 & 97 & .93 & 1.88 & 2.00 & 1.99 & 1.93 & 1.93 & 1.89 & 1.91 & 1.92 & 1.94 & 1.92 & 1.96 & 1.92 \\
\hline & 27.0 & 27.5 & 26.5 & 28.1 & 29.8 & 25.5 & 25.9 & 27.6 & 28.0 & 29.8 & 29.1 & 28.8 & 28.1 & 28.5 & 27.4 & 3.4 \\
\hline & .78 & 2.59 & 2.46 & 1.82 & 1.09 & 2.15 & 1.15 & 1.74 & 1.91 & 1.92 & 1.86 & 1.91 & 1.51 & 2.22 & 1.45 & 2.45 \\
\hline$-\mathrm{U}$ & 1.87 & 2.06 & 1.99 & 2.05 & 1.97 & 2.02 & 2.08 & 2.03 & 2.10 & 1.96 & 2.04 & 2.09 & 2.12 & 2.05 & 2.15 & 2.18 \\
\hline Y-UP & 1.89 & 2.20 & 2.15 & 2.17 & 2.06 & 2.13 & 2.47 & 2.08 & 2.13 & 2.04 & 2.12 & 2.27 & 2.38 & 2.34 & 2.47 & 2.30 \\
\hline Z-UPV(K & 1.87 & 1.85 & 1.97 & 1.91 & 1.87 & 1.91 & 2.03 & 1.90 & 1.94 & 1.94 & 1.93 & 1.96 & 1.81 & 1.97 & 1.90 & 1.95 \\
\hline$\kappa$ & 59 & 60 & 50 & 51 & 50 & 53 & 51 & 49 & 58 & 55 & 53 & 55 & 55 & 48 & 48 & 56 \\
\hline Specimens & 33 & 34 & 35 & 36 & 37 & 38 & 39 & 40 & 41 & 42 & 43 & 44 & 45 & 46 & 47 & 48 \\
\hline $\mathrm{D}(\mathrm{K}$ & 1.99 & 1.91 & 1.92 & 1.92 & 1.94 & 1.87 & 1.98 & 1.94 & 1.91 & 1.91 & 1.95 & 1.92 & 1.93 & 1.90 & 1.90 & 1.90 \\
\hline & 26.5 & 29.3 & 28.4 & 28.4 & 28.1 & 30.3 & 28.1 & 28.1 & 29.1 & 28.9 & 27.5 & 28.7 & 28.0 & 29.4 & 29.4 & 29.5 \\
\hline & & 1.95 & 3.15 & 1.39 & 0.41 & 0.71 & 2.0 & 2.79 & 1.32 & 1.89 & 3.00 & 2.98 & 1. & 2.86 & 2.38 & 2.25 \\
\hline X-L & 2.17 & 2.29 & 1.95 & 1.81 & 1.98 & 2.09 & 1.79 & 1.82 & 1.86 & 1.81 & 2.12 & 1.98 & 1.96 & 1.93 & 1.94 & 2.02 \\
\hline Y-UP & 2.30 & 2.39 & 2.23 & 2.13 & 2.14 & 2.06 & 2.19 & 1.84 & 1.96 & 1.98 & 2.21 & 2.18 & 2.20 & 2.31 & 2.19 & 2.34 \\
\hline Z-UPV(H & 1.99 & 2.06 & 1.84 & 2.04 & 1.95 & 2.01 & 1.87 & 1.86 & 1.87 & 1.87 & 1.92 & 1.98 & 1.91 & 1.75 & 1.80 & 1.79 \\
\hline $\mathrm{R}$ & 54 & 60 & 54 & 56 & 56 & 55 & 53 & 60 & 52 & 58 & 55 & 63 & 51 & 46 & 58 & 49 \\
\hline
\end{tabular}

\subsection{Ultrasonic pulse velocity and rebound index}

After curing for 28 days, the 48 cube A specimens were tested with the ultrasonic pulse device, to the $\mathrm{X}$ orientation (test tube 39), whereas the highest is $2.47 \mathrm{~km} / \mathrm{s}$ in the $\mathrm{Y}$ orientation (test tube 23). Further, Table 2 shows that the mean of UPV for all 48 test samples in the $X$ and $Y$ 
267 of 0.12 . Concerning the $Z$ orientation, its mean is $1.85 \mathrm{Km} / \mathrm{s}$, with a similar standard deviation.

In Table 1, mean values are represented for each set of readings related to each test samples of type $A$ at 28 days. It can be observed how $R$ values are comprehended within the interval $43-$ 67 , where the hammer is designed for a range $0-200$. Therefore, $R$ mean value is 55 , with a standard deviation of 5.33 (Table 2). Moreover, the coefficient of variation is $9.64 \%$, which is the second highest for all the studied variables, after that one of the variable CS, which is $34.24 \%$.

\subsection{Statistical analysis}

In order to assess the quality of rammed earth walls by means of NDT, and also to make further predictions for the case of this material, it has been carried out a regression analysis on the 48 samples that have previously been described. To this end, it has been made use of the statistical software Statgraphics Centurion. The regression analysis establishes the best statistical models (see Fig. 6) fitting the relationship between the dependent variable CS and each one of the four independent variables $R, X-U P V, Y$-UPV and Z-UPV. The coefficients of determination $\left(R^{2}\right)$ of these four models establish the dependent variable CS to be predictable, respectively, in $97.04 \%$, $96.68 \%, 96.76 \%$ and $96.83 \%$. 

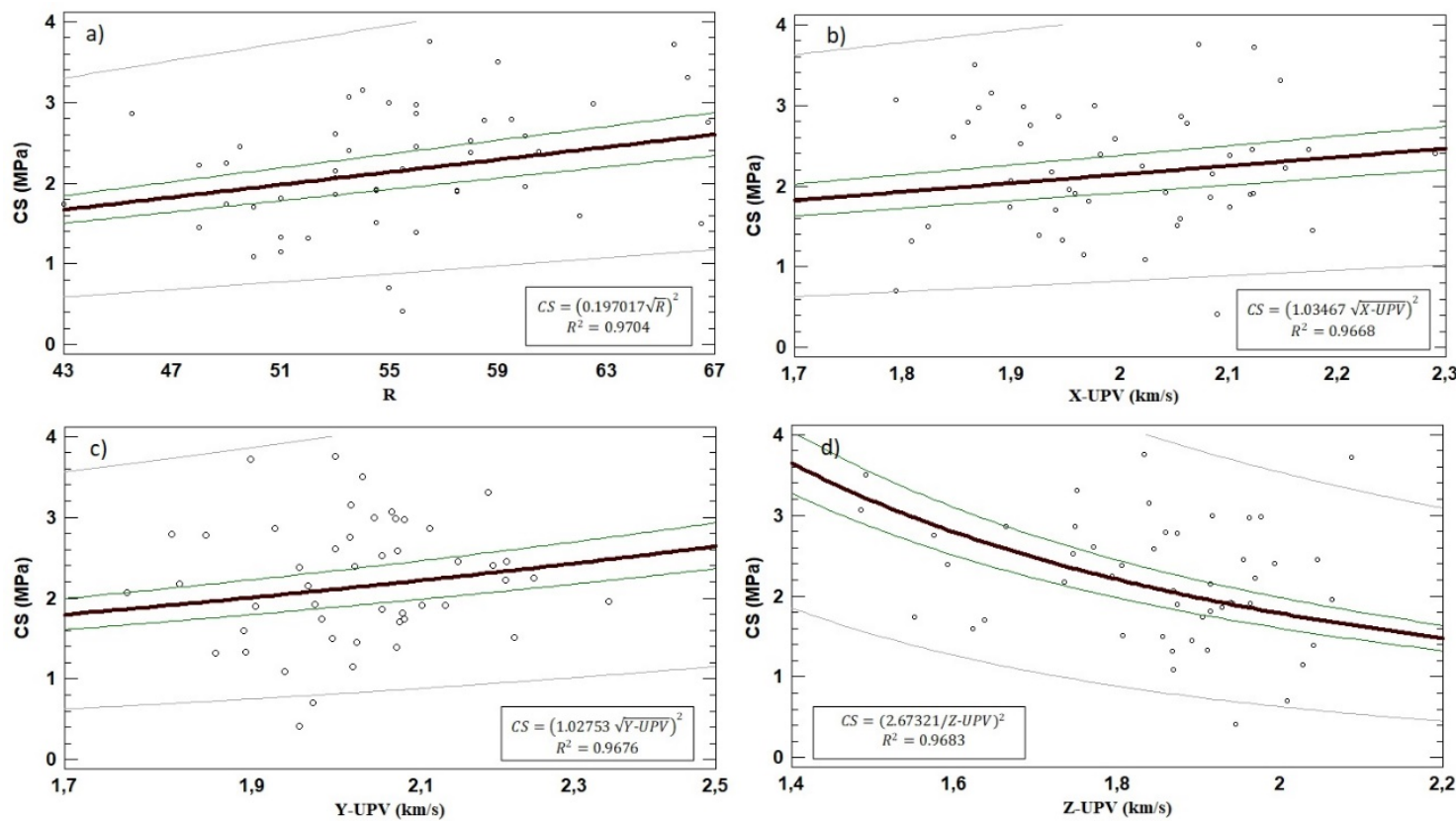

Figure 6. Regression analysis curves, being a) correlation between CS and R; b) Correlation between CS and X-UPV; c) Correlation between CS and Y-UPV, and d) Correlation between CS and Z-UPV.

In Figure 6, regression curves between the variable CS and each one of the four variables under consideration are shown in solid wide lines. The interval between both closest solid lines around each regression curve constitutes the $95 \%$ confidence interval for the CS mean of given samples, whereas that one between the two most distant solid lines around each regression curve determines the $95 \%$ confidence interval for predicted new observations. It can be observed in particular that almost all the samples in Figure 6 are within the $95 \%$ confidence intervals for predicted new observations.

On the other hand, it has also been carried out a second kind of regression model (in this case, a linear multivariate one) in order to determine the best relationship among the dependent variable CS and all the rest of variables R, X-UPV, Y-UPV and Z-UPV. With a 95\% confidence level and a $R^{2}$ of 0.9122 , such a model is given by the following equation:

$$
C S=0.613036 \cdot X-U P V+0.555896 \cdot Y-U P V-1.47851 \cdot Z-U P V+0.0469029 \cdot R
$$


Concerning this, for each one of the four independent variables ( $R, X-U P V, Y-U P V$ and Z-UPV), it is indicated in Table 3:

- The standard error of the residuals with respect to such a statistical model.

- The $p$-value, which indicates, in case of being greater than 0.05 , that an independent variable is not statistically significant within the linear model and hence, it could be removed from the equation without degrading the model. In this regard, observe that there are only two parameters with significant relevance in our statistical model: $R$ and Z-UPV.

\begin{tabular}{ccc}
\hline $\begin{array}{c}\text { Independent } \\
\text { variable }\end{array}$ & Standard error & p-value \\
\hline X-UPV & 0.870803 & 0.4851 \\
Y-UPV & 0.75761 & 0.4670 \\
Z-UPV & 0.689156 & 0.0375 \\
R & 0.016827 & 0.0078 \\
\hline
\end{tabular}

Table 4. Multivariate analysis among CS and the variables R, X-UPV, Y-UPV and Z-UPV.

Keeping in mind all the previous results, the study focused again on a linear regression model that determines the best statistical model fitting a linear relationship among the dependent variable CS and both variables $R$ and Z-UPV. With a $95 \%$ confidence level and a $R^{2}$ of 0.9111 , the just mentioned model is defined as follows:

$$
C S=-0.63456 \cdot Z-U P V+0.0610895 \cdot R
$$

The standard error of the residuals and the $p$-value of each independent variable are shown in Table 4. Observe that, according to its p-value, the independent variable Z-UPV could be removed from the resulting equation without degrading significantly the model. This agrees with the previously mentioned fact that the best coefficient of determination among the statistical models shown in Figure 6 was that one corresponding to Figure $6 a$, which ensures a $R^{2}$ of 0.9704 of the values of the dependent variable CS with respect to those of the independent variable $R$. 


\begin{tabular}{ccc}
\hline $\begin{array}{c}\text { Independent } \\
\text { variable }\end{array}$ & Standard error & p-value \\
\hline Z-UPV & 0.431325 & 0.148 \\
R & 0.01143954 & 0.0001 \\
\hline
\end{tabular}

\section{Discussion}

321 As it is detailed in Table 2, the standard deviations of all the three variables UPV are similar and smaller than that one of the variable $\mathrm{R}$, whereas the standard deviation of the variable CS is comprehended in an intermediate interval. Moreover, it can be observed how all the coefficients of variation are smaller than $20 \%$, except for that one of the variable CS, which becomes $34 \%$, giving rise to a higher dispersion of the data. Nevertheless, the highest coefficient of variation of the four variables under consideration ( $R, X-U P V, Y-U P V$ and Z-UPV) corresponds to the variable $R$, whose distribution is closer to that one of the variable CS. As such, it is confirmed again the fact that $\mathrm{R}$ is the most accurate variable in order to predict the values of the variable CS, as it was already indicated in the exposed statistical analysis.

Due to it, it can be ensured the existence of separate relationships among these variables derived from both proposed NDT. Although the coefficient of determination of $\mathrm{R}$ is similar to those corresponding to UPV, the rebound hammer results turn out to be statistically more accurate than UPV readings to predict CS. In this regard, it is well known the set of factors that have influence on UPV (see appendix B of [15]), such as water in pores, temperature, shape and size of the sample or internal cracks. Since these issues are related to a heterogeneous mass, the readings from ultrasonic pulse test may be uneven.

With respect to the rebound test, among other parameters, the condition of the surface may be highlighted for playing a major role in the performance of the results. Other parameters, such as the dosage, moisture content, weight, slenderness, age, and tensional state imply variations on the readings, but in this case, all of them are have been controlled for the sample population, as it is discussed in the section of material and methods. If the sample is well anchored, avoiding 
shifting, and the testing surface meets certain simple criteria that will be explained, readings tend to be uniform and hence the correlation with the CS becomes more accurate.

344 The established equation for Z-UPV regarding with the univariate analysis is inversely 345 proportional to CS, being by the contrary X-UPV and Y-UPV directly proportional. As discussed by [42], in terms of mechanical performance, rammed earth could be considered an anisotropic material in certain situations. It is also known the relation between the Young Modulus (E) and UPV, by which the more UPV, the greater E value $[17,43]$. Certain equations has been proposed, such as [17] to establish these parameters in the case of earthen materials. Other studies, such as [44], have suggested that, in case of highly porous building limestone, a reliable linear correlation between UPV and CS exists. In this study, the regression analysis between X-UPV and Y-UPV becomes the best fitting equation where the aforementioned relation is followed. Nevertheless, in the case of Z-UPV, the best fitting equation implies a reverse relation, since a greater UPV corresponds to a lesser CS, for which the corresponding coefficient of determination is 0.9683 . Nevertheless, this physical-mechanical behaviour is not in accordance with the stated soil mechanics as an isotropic material that has been claimed by certain authors [42]. If current data of Z-UPV is to be adjusted to a linear model similar to X-UPV and Y-UPV, the alternative mathematical regression (Fig. 7) would present a lower correlation coefficient $\left(R^{2}=\right.$ 0.87). Therefore, in order to confirm this above-mentioned result, it would be necessary to carry out further research to obtain a wider range of dataset for Z-UPV and CS. For instance, it would also be considered other rates of compaction bellow and above the given maximum dry density that was established for the 48 samples $\left(2.04 \mathrm{gr} / \mathrm{cm}^{3}\right)$. Since the proposed methodology to manufacture samples by manual ramming involves the number of strokes, by configuring different numbers, several compaction sets will be achieved. The resulted data might draw a more complete scatter plot so that a clearer tendency would be obtained for Z-UPV. 


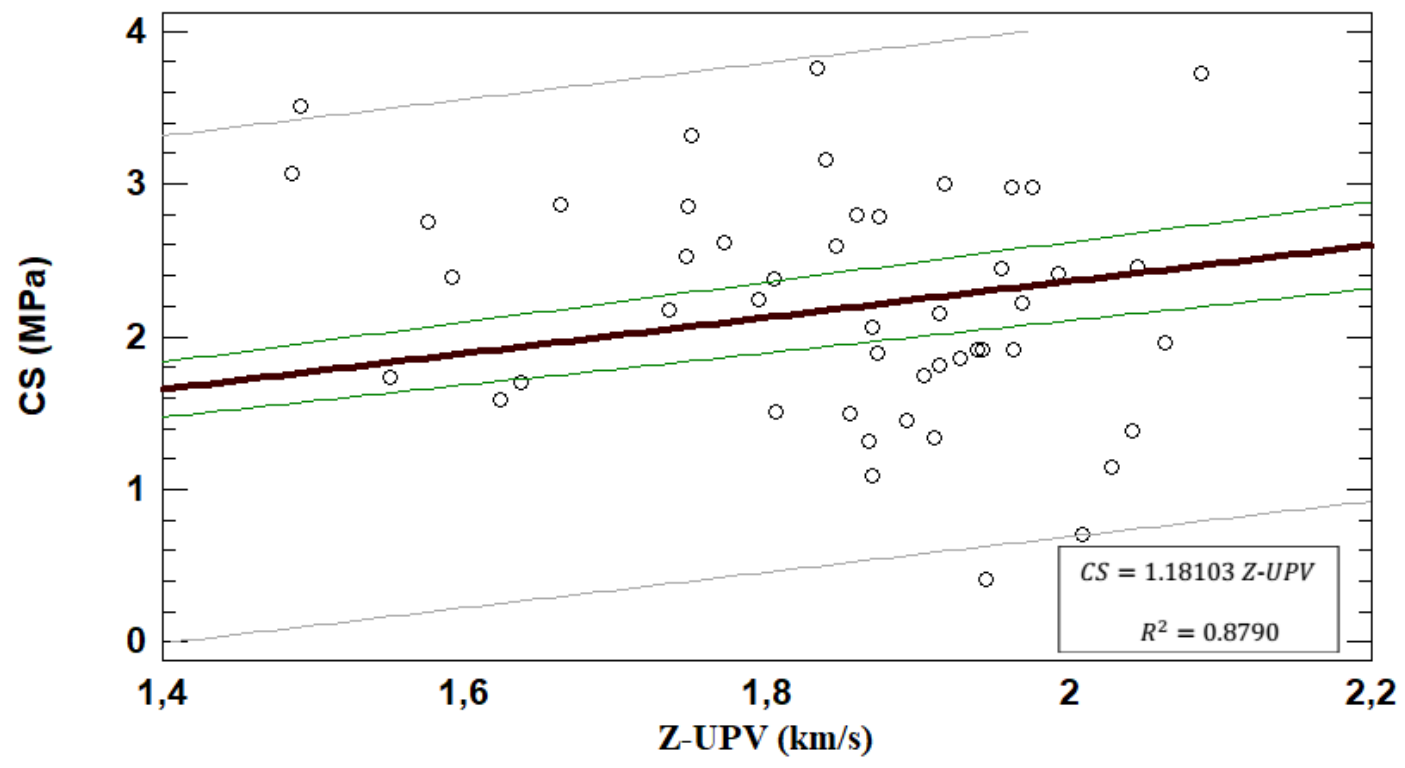

366

Figure 7. Alternative regression model for the correlation between CS and Z-UPV.

368 If mean values are evaluated separately for X-UPV, Y UPV and Z-UPV, it can be observed that X and $Y$ orientation show similar values, namely $2.00 \mathrm{~km} / \mathrm{s}$ and $2.03 \mathrm{~km} / \mathrm{s}$, while Z-UPV yield a value of $1.85 \mathrm{~km} / \mathrm{s}$. The possible cause of this minor difference may rely on the uneven surface of the top face of the samples. The UPV readings carried out in the $X$ and $Y$ directions always involved regular and flat surfaces since all faces were in contact with the formwork. Nevertheless, for Z-UPV the top face was indeed where compaction took place, so UPV probes did not adjust as smoothly as for $\mathrm{X}$ and $\mathrm{Y}$ directions, even if considering the use of a coupling material for the UPV probes. However, further research is needed to discard or confirm this hypothesis.

The multivariate analysis that has been made in this study establishes a coefficient of determination $\mathrm{R}^{2}$ of 0.9122 among the variable CS and the rest of variables under consideration. This enables us to ensure a linear dependence among all the variables. Observe that this assertion is completely true in case of dealing with each one of the four variables, namely XUPV, Y-UPV, Z-UPV and R, which are zero whenever the variable CS is zero. The multivariate analysis among the variables CS, R and the variable Z-UPV established a coefficient of determination $\mathrm{R}^{2}$ of 0.9111 , which is less than the coefficient of determinations resulting from 
the aforementioned regression analysis. Even if the former is a high value, this fact determines that both NDT ( $R$ and UPV) are not supplementary to establish a relationship with the variable CS. Hence, in case of being interested in predicting the value of the compressive strength of a rammed-earth wall by means of NDT, the use of the rebound index is more accurate by itself than complementing it with the ultrasonic pulse velocity.

The procedure that has been implemented in this study in order to determine the compressive strength of lime-stabilised rammed-earth walls by means of NDT, has been confirmed by means of a statistical analysis. Such a procedure has been designed according to two referred standard of concrete, UNE-EN 12504-2 and UNE-EN 12504-4, for R and UPV, respectively. Keeping in mind the heterogeneity of rammed-earth materials, it has been necessary to adapt the initial criteria in order to validate the readings obtained by UPV with respect to the referred standards. The latter establishes that the variation of readings has to be smaller than $1 \%$ with respect to the mean in order to be valid. In this study, this value has been increased up to $10 \%$ in order to get accurate readings in all the directions and without implying a high dispersion of data. The statistical analysis shows that UPV values of samples are homogeneous and give rise to an accurate coefficient of variation (see Table 2). Nevertheless, it is considered that the number of readings per specimen should be greater than the regulated one. The authors recommend a minimum of 4 readings per each direction, namely $X, Y$, and $Z$, for cubic test tubes with $15 \mathrm{~cm}$ on each side.

On the other hand, R has been dealt with in this study according to the UNE-EN 12504-2 standard [39], without establishing any modification of the criteria for the reading validation. The execution of the corresponding test requires the following remarkable criteria: (a) to save the separation distances above commented with the sample borders and between each impact area; (b) to have a number of representative readings (16-20 readings have demonstrated suitable); and (c) to keep in mind that no more than $20 \%$ of readings must be greater than $30 \%$ of the median value. Moreover, it is confirmed the influence of the $R$ in the $D$, as Bui suggested 
410 in [21]. In consequence, it is important not to repeat readings over the same area. In fact, the

411 analysed specimens enable us to ensure a linear statistical dependence between both variables

$412 \quad R$ and $D$, because the corresponding linear regression establishes a $R^{2}$ value of 0.9913 .

\section{Conclusions}

414 This research analysed the physical-mechanical properties and their relationship with ultrasounds and rebound hammer index for a specific composition of lime-stabilised rammed earth. The following conclusions may be drawn from the analysis of results:

Ultrasound and rebound hammer index are complementary non-destructives techniques that can be used to qualitatively evaluate the quality of execution of a rammed-earth wall. In order to obtain a quantitative evaluation it would be necessary to modify certain fixed parameters, such as different rates of compaction for the same dosage. In any case, these results would only be valid to evaluate that precise type of material.

The developed statistical analysis gives rise to a coefficient of determination among variables that ensures an accurate prediction of the behaviour of the compressive strength by means of both NDT. In fact, the equations and its corresponding plots proposed in the statistical analysis may be used as calibration curves for this kind of lime-stabilised rammed earth. accurate test to evaluate the variable CS, but it does not improve the rebound index test.

Finally, it has been statistically proved the accuracy of the proposed procedure to determine both variables UPV and R by means of NDT according to the current UNE standards.

430 Nevertheless, in case of dealing with UPV, the authors recommend a minimum of $10 \%$ of reading dispersion, due to the fact that rammed earth is more heterogeneous than concrete. 
433 The authors wish to acknowledge the work of Borja Sánchez Luna for his contribution during the

434 manufacturing of specimens and the elaboration of some results.

\section{References}

[1] R. Eires, A. Camões, S. Jalali, Enhancing water resistance of earthen buildings with quicklime and oil, J. Clean. Prod. (2016). doi:10.1016/j.jclepro.2016.10.141.

[2] J. Cid-Falceto, F.R. Mazarrón, I. Cañas, Assessment of compressed earth blocks made in Spain: International durability tests, Constr. Build. Mater. 37 (2012) 738-745. doi:10.1016/j.conbuildmat.2012.08.019.

[3] A. Suresh, K.B. Anand, Strength and Durability of Rammed Earth for Walling, J. Archit. Eng. 23 (2017) 06017004. doi:10.1061/(ASCE)AE.1943-5568.0000281.

[4] G.-S. Yan, H.-Y. Zhang, X.-D. Wang, B. Yang, M. Li, Durability of earthen architecture ruins under cyclic freezing and thawing, Yantu Lixue/Rock Soil Mech. 32 (2011) 2267-2273. http://www.scopus.com/inward/record.url?eid=2-s2.080052108177\&partnerID=40\&md5=fca6bb05b946a371f351321f97547ba2.

[5] H. Schroeder, Sustainable Building with Earth, Springer, Cham, 2016. http://search.ebscohost.com/login.aspx?direct=true\&db=nlebk\&AN=1074262\&lang=es \&site=ehost-live \&scope=site.

[6] NZS 4298, NZS 4298 (1998): Materials and workmanship for earth buildings, 4298 (1998) 91.

[7] UNE-EN-12504-1, Testing concrete in structures - Part 1: Cored specimens - Taking, examining and testing in compression, AENOR. (2009).

[8] UNE-EN-1015-11, Methods of test for mortar for masonry - Part 11: Determination of flexural and compressive strength of hardened mortar, 2000.

[9] B. Linda, C. Modena, Evaluation and strengthening of existing masonry structures: proceedings of the Join International Workshop proposed by RILEM TC 127-MS Test for Masonry Materials ans Structures and CIB W23 Wall Structures, RILEM, [Francia?] :, 1997. http://fama.us.es/record=b1985113 S5*spi (accessed June 29, 2016).

[10] J.J. Martín-del-Rio, V. Flores-Alés, F.J. Alejandre-Sánchez, F.J. Blasco-López, New Method for Historic Rammed-earth Wall Characterization: The Almohade Ramparts of Malaga and Seville, Stud. Conserv. (2018) 1-10. doi:10.1080/00393630.2018.1544429.

[11] D. Ciancio, J. Gibbings, Experimental investigation on the compressive strength of cored and molded cement-stabilized rammed earth samples, Constr. Build. Mater. 28 (2012) 294-304. doi:10.1016/j.conbuildmat.2011.08.070.

[12] F.J. Alejandre, J.J. Martín del Río, J. Blasco López, V. Flores, J.J. del Río, J.B. López, V. Flores, Methodological proposal for rammed-earth wall characterization: Understanding of material in preliminary studies, in: Rammed Earth Conserv. - Mileto, Vegas Cris., Taylor \& Francis Group, London, ISBN 978-0-415-62125-0, 2012: pp. 41-46.

[13] P. Walker, The Australian Earth building handbook, Standards Australia International, Sydney :, 2001.

[14] I. Lombillo, L. Villegas, E. Fodde, C. Thomas, In situ mechanical investigation of rammed 
earth: Calibration of minor destructive testing, Constr. Build. Mater. 51 (2014) 451-460. doi:http://dx.doi.org/10.1016/j.conbuildmat.2013.10.090.

[15] UNE-EN-12504-4, Testing concrete. Part 4: Determination of ultrasonic pulse velocity, España, 2004.

[16] UNE-EN-13791:2009, Assessment of in-situ compressive strength in structures and precast concrete components, Spain, 2009.

[17] E. Bernat-Maso, E. Teneva, C. Escrig, L. Gil, Ultrasound transmission method to assess raw earthen materials, Constr. Build. Mater. 156 (2017) 555-564. doi:10.1016/j.conbuildmat.2017.09.012.

[18] M. De Fino, G. De Tommasi, F. Fatiguso, Experimental studies to normalize the sonic test

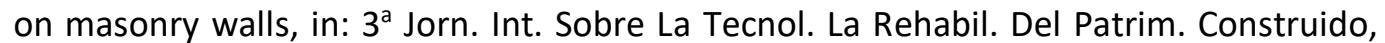
Grupo GTED-UC de la Universidad de Cantabria, Bilbao, 2009: pp. 325-340.

[19] J. Canivell, J.J. Martin-del-Rio, F.J. Alejandre, J. García-Heras, A. Jimenez-Aguilar, Considerations on the physical and mechanical properties of lime-stabilized rammed earth walls and their evaluation by ultrasonic pulse velocity testing, Constr. Build. Mater. 191 (2018) 826-836. doi:10.1016/j.conbuildmat.2018.09.207.

[20] Q.-B. Bui, R. El-Nabouch, P. Perrotin, O. Plé, Assessing a Nondestructive Method to Determine the Young's Modulus of Rammed Earth Material, in: Poromechanics 2017 Proc. 6th Biot Conf. Poromechanics, 2017. doi:10.1061/9780784480779.106.

[21] Q.-B. Bui, Assessing the Rebound Hammer Test for Rammed Earth Material, Sustainability. 9 (2017) 1904. doi:10.3390/su9101904.

[22] R. Liang, G. Hota, Y. Lei, Y. Li, D. Stanislawski, Y. Jiang, Nondestructive evaluation of historic hakka rammed earth structures, Sustain. 5 (2013) 298-315. doi:10.3390/su5010298.

[23] A. Kailey, G. Rishi, Current state of modern rammed construction: A case study of first peoples house after seven years exposure, 666 (2016) 63-76. doi:10.4028/www.scientific.net/KEM.666.63.

[24] F. Volhard, U. Röhlen, Lehmbau Regeln (Dachverband Lehm e.V), 3rd ed., Springer Vieweg Verlag, Wiesbaden, 2009.

[25] P. Walker, R. Keable, J. Martin, V. Maniatidis, Rammed Earth. Design and construction guidelines, BRE bookshop, Watford, 2005.

[26] E. Baglioni, F. Fratini, L. Rovero, The characteristics of the earthen materials of the Drâa valley's architecture, J. Mater. Environ. Sci. 7 (2016) 3548-3546.

[27] L. Mateus, M.R. Veiga, J. De Brito, In situ characterization of external ancient renderings of rammed earth constructions in the Algarve and of potential ... In situ characterization of external ancient renderings of rammed earth constructions in the Algarve and of potential replacement com, in: LEHM 2016. 7th Int. Conf. Build. with Earth, Springer, Wiemar, 2016.

[28] M. Hall, Y. Djerbib, Rammed earth sample production: Context, recommendations and consistency, Constr. Build. Mater. 18 (2004) 281-286. doi:https://doi.org/10.1016/j.conbuildmat.2003.11.001.

[29] C.M. Martins Neves, O. Faria, Técnicas de construcción con tierra, FEB-UNESP, PROTERRA, Bauru, 2011. http://www.redproterra.org/.

[30] UNE-EN 933-1:2012, Tests for geometrical properties of aggregates - Part 1: 
[31] UNE 103-103-94, Determination of the liquid limit of a soil by the Casagrande apparatus method., España, 1994.

[32] UNE 103-104-93, Test for plastic limit of a soil, España, 1993.

[33] UNE-EN 13039:2012, Soil improvers and growing media. Determination of organic matter content and ash, Spain, 2009.

[34] A. Walkley, C.A. Black, An examination of the Degtjareff method for determining soil organic matter and a proposed modification of the chromic acid titration method, Soil Sci. 37 (1934) 29-38.

[35] UNE-103-500-94, UNE 103-500-94: Geotechnic. Compaction test. Standard Proctor, 1994.

[36] UNE-EN-ISO-17892-1, Geotechnical investigation and testing. Laboratory testing of soil. Part 1: Determination of water content, 2015.

[37] D. Ciancio, P. Jaquin, P. Walker, Advances on the assessment of soil suitability for rammed earth, Constr. Build. Mater. 42 (2013) 40-47. www.scopus.com.

[38] UNE-EN-1936:07, Natural stone test methods - Determination of real density and apparent density, and of total and open porosity, 2007.

[39] UNE-EN 12504-2:2013, Testing concrete in structures. Part 2: Non-destructive testing. Determination of rebound number, 2013.

[40] F. Champiré, A. Fabbri, J.C. Morel, H. Wong, F. McGregor, Impact of relative humidity on the mechanical behavior of compacted earth as a building material, 110 (2016) 70-78. doi:10.1016/j.conbuildmat.2016.01.027.

[41] F.J. Alejandre, Caracterización analítica de un muro de tapial correspondiente al complejo edilicio de carácter monumental de época Almohade, in: San Juan Acre La Hist. Recuper. Un Barrio Sevilla. Ed. Rodríguez Azogue, Araceli, Aycart Luengo, Vicente., A. Rodríguez, Sevilla:, 2007: p. 245. http://fama.us.es/record (accessed September 12, 2017).

[42] Q.B. Bui, J.C. Morel, Assessing the anisotropy of rammed earth, Constr. Build. Mater. 23 (2009) 3005-3011. doi:10.1016/j.conbuildmat.2009.04.011.

[43] R. Huete-Fuertes, P. Rubio-de-Hita, C. Rodríguez-Liñán, Aplicación de los métodos de ultrasonidos a la verificación de materiales de construcción, Rev. Edif. RE. 13 (1993) 922. http://dadun.unav.edu/handle/10171/16517 (accessed May 27, 2019).

[44] E. Vasanelli, D. Colangiuli, A. Calia, M. Sileo, M.A. Aiello, Ultrasonic pulse velocity for the evaluation of physical and mechanical properties of a highly porous building limestone, Ultrasonics. 60 (2015) 33-40. doi:10.1016/J.ULTRAS.2015.02.010. 